\title{
Residual myocardial jeopardy in patients with Q-wave and non-Q-wave infarctions
}

\author{
J K BISSETT, * J MATTS, $†$ BIMLENDRA SHARMA, * PROGRAM ON SURGICAL \\ CONTROL FOR HYPERLIPIDEMIA-STUDY GROUP (POSCH) $\ddagger$
}

From the Departments of Medicine and Surgery, ${ }^{\star}$ University of Arkansas School of Medicine, $\dagger$ University of Minnesota School of Medicine, Little Rock, Arkansas, USA

SUMMARY The correlation between the presence of areas of jeopardised myocardium and the electrocardiographic patterns of anterior and inferior $Q$-wave and non-Q-wave infarctions was studied in 486 patients who had had stable symptoms for at least six months after a single myocardial infarction. Myocardial jeopardy was identified on a ventriculogram in the right anterior oblique position if normal or hypokinetic wall motion was seen in all segments distal to a lesion that caused stenosis of $>50 \%$ and $<100 \%$ in the proximal or mid left anterior descending coronary artery (anterior jeopardy), or in the proximal or mid right coronary artery or proximal circumflex coronary artery in a left dominant circulation (inferior jeopardy). Patients with nonQ-wave anterior infarctions had a significant increase in the frequency of jeopardised myocardium when compared with patients with $Q$-wave inferior or anterior infarctions. The group with non-Q-wave anterior infarction also had a significantly lower percentage of myocardial segments with absent wall motion in the area of infarction than all other groups.

This combination of coronary narrowing with retained wall motion may contribute to the increased frequency of reinfarction seen in some studies of non-Q-wave infarction.

Viable myocardium distal to significantly diseased coronary vessels is regarded as being at jeopardy of infarction. The presence of jeopardised myocardium may influence therapeutic decisions about cardiovascular surgery. Analysis of variables associated with a decision to operate showed that the myocardial jeopardy score was ranked first by seven of fifteen investigators in a large multicentre study. ${ }^{1} \mathrm{~A}$ recent study has demonstrated a strong correlation between haemodynamic changes during atrial pacing

\footnotetext{
$\ddagger$ Members of the POSCH group.

Coordinating Centre: John M Long, John P Matts, Laurie L Fitch.

Administration: Bernard A Ley, Betty Hansen.

Data Monitoring Committee: Thomas C Chalmers (Chairman), Jacob E Bearman, C Richard Conti, Gerald R Cooper, Samuel W Greenhouse, J Ward Kennedy, Paul Meier, Curtis L Meinert, Jeffrey Probstfield, Jeremiah Stamler, D Eugene Strandness.

Mortality Review Committee: Jesse E Edwards (Chairman), David Spain, Lawrence S C Griffith, Arthur J Moss

Policy and Data Monitoring Board: Antonio M Gotto Jr, Daniel Steinberg (Co-Chairmen), James J Leonard, C Morton Hawkins, Elliot Rapaport, Doris Tulcin, David L Sylwester, Robert Zeppa.

Consultants: David H Blankenhorn, William L Holmes, Richard B Moore, Manford Morris.
}

Requests for reprints to Dr J K Bissett, Department of Medicine, University of Arkansas School of Medicine, 4301 West MarkhamMail Slot 532, Little Rock, Arkansas 72205, USA.

Accepted for publication 22 June 1987 and the amount of left ventricular myocardium at jeopardy of coronary ischaemia. ${ }^{2}$

The results of these studies emphasise the close relation between jeopardised myocardium, haemodynamic impairment, and the concern of the physician to preserve left ventricular function. We have compared myocardial jeopardy scores in patients with a single $Q$-wave or non-Q-wave infarction in a large homogenous group of patients who had survived at least six months after a single documented myocardial infarction. The results illustrate the predictive ability of electrocardiogram patterns and provide an indication of the type and extent of myocardial jeopardy to be expected in patients with stable symptoms after myocardial infarction.

\section{Patients and methods}

\section{METHODS}

The Program on Surgical Control of Hyperlipidemia (POSCH) is a multicentre randomised trial of cholesterol reduction by partial ileal bypass to prevent morbidity and mortality after an initial myocardial infarction. ${ }^{3}$ Baseline studies were performed on 486 patients entered into the study 
protocol. All patients had sustained a single myocardial infarction six months to five years before entry into the study. The diagnosis of infarction was based on characteristic clinical symptoms; the presence of serial electrocardiograms demonstrating new Q-waves or T-wave changes; and serum creatine kinase, serum glutamic oxalacetic transaminase, or lactic dehydrogenase values of at least twice the upper limit of normal. Additional study criteria included ages between 30 and 65 , serum cholesterol greater than $220 \mathrm{mg} / \mathrm{dl}$ or between $200 \mathrm{mg} / \mathrm{dl}$ and $219 \mathrm{mg} / \mathrm{dl}$ with concentrations of low density lipoprotein greater than $140 \mathrm{mg} / \mathrm{dl}$. Patients with unstable angina, valvar disease, congestive failure, uncontrolled hypertension, and diabetes were excluded.

Electrocardiograms taken during hospital admission for acute myocardial infarction were independently interpreted by two cardiologists who measured the area of ST-T changes according to the Minnesota code. If they did not agree the final decision was made by a third cardiologist.

We studied 411 patients with a $Q$-wave infarction and 75 patients with a non-Q-wave infarction. Terminology in this study is similar to that given by Spodick. ${ }^{4} \mathrm{~A}$ All patients with a non- $Q$-wave anterior infarction $(n=40)$ and a $Q$-wave anterior infarction $(n=158)$ had both anterolateral and anteroseptal electrocardiographic changes. The remaining 35 patients with non-Q-wave infarction and 253 patients with Q-wave infarction had electrocardiographic patterns of inferior or inferior and posterior infarction. Patients with electrocardiographic changes in a single anterior area or changes in both anterior and inferior areas were not included in this report.

All patients were studied by coronary angiography from the brachial or femoral approach. The coronary arteriogram and left ventriculogram were evaluated independently without knowledge of the electrocardiographic results. All readings were completed by the study's central arteriography laboratory at the University of Minnesota. Myocardial jeopardy was defined by the criteria used in the Coronary Artery Surgery Study (CASS). ${ }^{1}$ Left ventricular injection was performed in the right anterior oblique position. The left ventricle was then divided into six equal segments. Wall motion was graded as either retained (normal or hypokinetic) or absent (akinetic or dyskinetic). The extent of myocardial change was estimated for the approximate area of infarction as percentage of left ventricular segments with absent wall motion (number of akinetic or dyskinetic segments divided by four for anterior myocardial infarction or divided by two for inferior myocardial infarction).
Anterior myocardial jeopardy was defined as retained wall motion in all four anterior and anteroapical segments (normal or hypokinetic motion in segments 1-4) distal to a proximal or mid left anterior descending lesion causing a $\geqslant 50 \%$ but $<100 \%$ reduction in vessel diameter. Jeopardy of the inferior surface was judged to be present when normal or hypokinetic wall motion was present both in segments 5 and 6 distal to a similar lesion in the proximal or mid portion of the right coronary artery or proximal circumflex branch in a left dominant system.

The extent of coronary vascular disease was also classified by the number of significantly diseased arteries (one to three). We excluded patients in whom clinically significant disease of the left main coronary artery was seen on the angiogram performed at the time of entry into the study. Continuous baseline variables were compared by analysis of variance. If a significant $(p<0.05)$ difference was found Student's $t$ test for unpaired samples was used to analyse all possible comparisons. The extent of wall motion abnormalities and presence of areas of myocardial jeopardy were compared by a standard $\chi^{2}$ test. Results are given as mean (1 SD).

\section{Results}

No significant differences were found in age at randomisation in patients with non- $Q$-wave anterior infarction (52.9 (7.1) years), Q-wave anterior infarction (51.4 (7.4) years), non-Q-wave inferior infarction (52.7 (7.6) years), and Q-wave inferior infarction (50.6 (7.7) years). The male to female ratio ranged from 9.0 in those with $Q$-wave anterior infarction to 16.5 in the group with non-Q-wave inferior infarction and was not significantly different among the groups studied. The mean number of coronary vessels with at least $50 \%$ obstruction was $1.6(0.2)$ per group and there was no significant difference between groups. The mean time of randomisation from initial myocardial infarction was 28 (1.2) months (range 26.9-29.6 months).

Table 1 shows baseline clinical variables. The differences in systolic and diastolic pressures were statistically significant (systolic $\mathrm{p}<0.05$; diastolic $p<0.01$ ). Left ventricular ejection fraction was significantly greater in patients with non-Q-wave infarctions. Tabulation of the percentage of patients with coronary collaterals showed that more of the group with Q-wave inferior infarctions had areas of jeopardised myocardium when compared with those who had non- $Q$-wave anterior infarctions $(p<0.05)$ and $Q$-wave anterior infarctions $(p<0.001)$. Concentrations of high density lipoproteins were slightly lower in patients with non-Q-wave inferior and $Q$ - 
Table 1 Baseline clinical data (mean (1SD))

\begin{tabular}{|c|c|c|c|c|c|}
\hline & $\begin{array}{l}\text { Non- } Q \text { wave } \\
\text { anterior } \\
(n=40)\end{array}$ & $\begin{array}{l}\text { Q-wave } \\
\text { anterior } \\
(n=158)\end{array}$ & $\begin{array}{l}\text { Non- } Q \text { wave } \\
\text { inferior } \\
(n=35)\end{array}$ & $\begin{array}{l}Q \text {-wave } \\
\text { inferior } \\
(n=253)\end{array}$ & $p^{\star}$ \\
\hline $\begin{array}{l}\text { Systolic BP (mmHg) } \\
\text { Diastolic BP (mmHg) } \\
\text { HDL (mg/dl) } \\
\text { Ejection fraction (\%) } \\
\text { Collateral circulation }(\%)\end{array}$ & $\begin{array}{l}124 \cdot 1(17 \cdot 0) \\
79 \cdot 3(9 \cdot 0) \\
41 \cdot 3(8 \cdot 4) \\
65 \cdot 2(11 \cdot 8) \\
50 \cdot 0\end{array}$ & $\begin{array}{r}117 \cdot 3(15 \cdot 3) \\
75 \cdot 0(8 \cdot 8) \\
42 \cdot 2(11 \cdot 3) \\
51 \cdot 7(14 \cdot 4) \\
51 \cdot 3\end{array}$ & $\begin{array}{r}118 \cdot 8(14 \cdot 5) \\
74 \cdot 7(10 \cdot 9) \\
37 \cdot 7(6 \cdot 9) \\
62.6 \quad(8 \cdot 9) \\
54 \cdot 3\end{array}$ & $\begin{aligned} 121 \cdot 1 & (14 \cdot 3) \\
77 \cdot 7 & (9 \cdot 8) \\
39 \cdot 5 & (9 \cdot 6) \\
56 \cdot 9 & (11 \cdot 3) \\
67 \cdot 6 & \end{aligned}$ & $\begin{array}{l}p<0.05 \\
p<0.01 \\
p<0.05 \\
p<0.001 \\
p<0.01\end{array}$ \\
\hline
\end{tabular}

*Analysis of variance.

BP, blood pressure; HDL, high density lipoproteins.

wave inferior infarctions than in patients with Qwave anterior infarctions.

One hundred and twelve patients reported taking $\beta$ blocking agents at the time of initial randomisation. Patients with Q-wave anterior infarctions (23/158; $15 \%$ ) were less likely to be on blocking drugs than patients with non-Q-wave anterior infarctions $(10 / 40 ; 25 \%), Q$-wave inferior infarctions (68/253; $27 \%$ ), or non-Q-wave inferior infarctions $(11 / 35$; $31 \%$ ). These differences did not reach statistical significance. One hundred and fifty patients were on antianginal drugs that might affect coronary blood flow: non-Q-wave anterior 13/40 (33\%), Q-wave anterior $49 / 158(31 \%)$, non-Q-wave inferior $13 / 35$ $(37 \%)$, and Q-wave inferior 75/253 (30\%). A significantly greater proportion of patients with nonQ-wave inferior infarctions received these drugs than the group with Q-wave inferior infarctions $(p<0.05)$. These drugs were predominantly nitrates; calcium channel antagonists were taken by only $5 \%$ of all patients studied.

Table 2 Patients with residual jeopardised myocardium in the area of previous infarction

\begin{tabular}{lllll}
\hline & $\begin{array}{l}\text { Non- } Q \text { wave } \\
\text { anterior } \\
(n=40)\end{array}$ & $\begin{array}{l}Q \text {-wave } \\
\text { anterior } \\
(n=158)\end{array}$ & $\begin{array}{l}\text { Non-Q wave } \\
\text { inferior } \\
(n=35)\end{array}$ & $\begin{array}{l}Q \text {-wave } \\
\text { inferior } \\
(n=253)\end{array}$ \\
\hline $\begin{array}{l}\text { Anterior } \\
\text { Inferior }\end{array}$ & $20(50 \cdot 0 \%)^{\star}$ & $28(17 \cdot 7 \%)$ & $\overline{9(25 \cdot 7 \%)}$ & $\overline{47}(18.6 \%)$ \\
\hline
\end{tabular}

${ }^{\star} \mathrm{p}<0.01$ vs $\mathrm{Q}$-wave anterior or inferior infarctions.

Table 3 Percentage of left ventricular segments showing no wall motion

\begin{tabular}{lllll}
\hline & $\begin{array}{l}\text { Non-Q wave } \\
\text { anterior } \\
(n=40)\end{array}$ & $\begin{array}{l}Q \text {-wave } \\
\text { anterior } \\
(n=158)\end{array}$ & $\begin{array}{l}\text { Non-Q wave } \\
\text { inferior } \\
(n=35)\end{array}$ & $\begin{array}{l}Q \text {-wave } \\
\text { inferior } \\
(n=253)\end{array}$ \\
\hline $\begin{array}{l}\text { Segments } \\
\text { in infarct } \\
\text { area without } \\
\text { retained wall } \\
\text { motion }(\%)\end{array}$ & $3(10)^{\star}$ & $33(32) \dagger$ & $20(35) \ddagger$ & $42(43)$ \\
\hline
\end{tabular}

$\star_{\mathrm{p}}<0.01$ vs all other groups.

$t \mathrm{p}<0.05$ vs non-Q-wave and $\mathrm{Q}$-wave inferior infarction. $\ddagger \mathrm{p}<0.01$ vs $\mathrm{Q}$-wave inferior infarction.
Tables 2 and 3 and figures 1 and 2 show the relation between myocardial jeopardy and the electrocardiographic pattern. Patients with non-Q-wave anterior infarctions had a higher cumulative frequency of residual myocardial jeopardy in the presumed area of infarction than either Q-wave anterior or inferior infarctions $(50.0 \%$ vs $17.7 \% ; \mathrm{p}<0.01$ and $50.0 \%$ vs $18.6 \%$; $<<0.01$ respectively). The frequency of jeopardised myocardium in non-Q-wave inferior infarction was compared with that in Qwave infarctions. Myocardial jeopardy was present

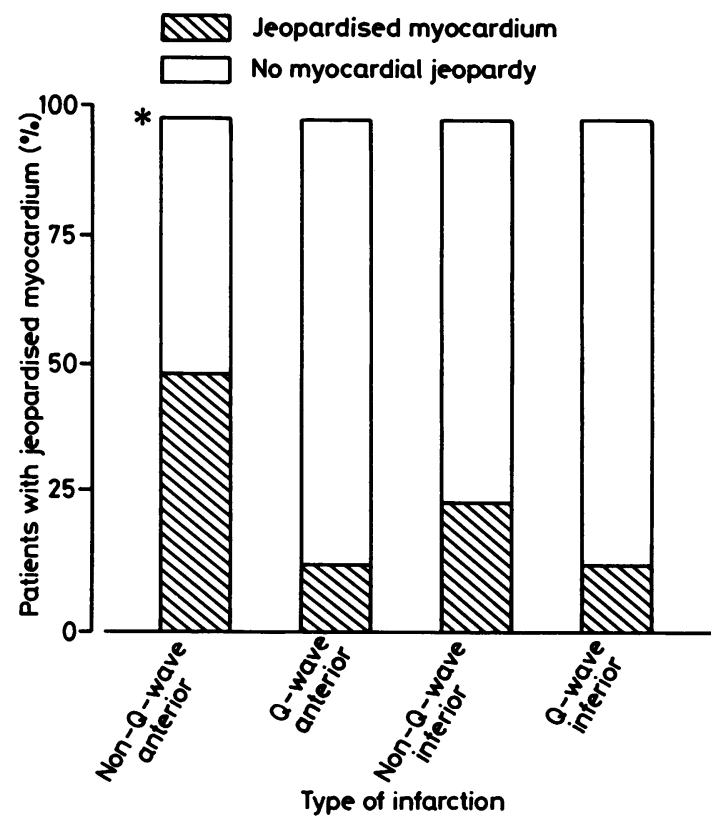

Fig 1 Frequency of residual myocardial jeopardy. The percentage of patients with retained wall motion in the area of infarction distal to coronary lesions of $>50 \%$ and $<100 \%$ is shown. In patients with anterior non-Q-wave patterns the frequency of residual jeopardised myocardium was significantly increased.

${ }^{\star} p<0.01$ vs $Q$-wave anterior and inferior myocardial infarction. 


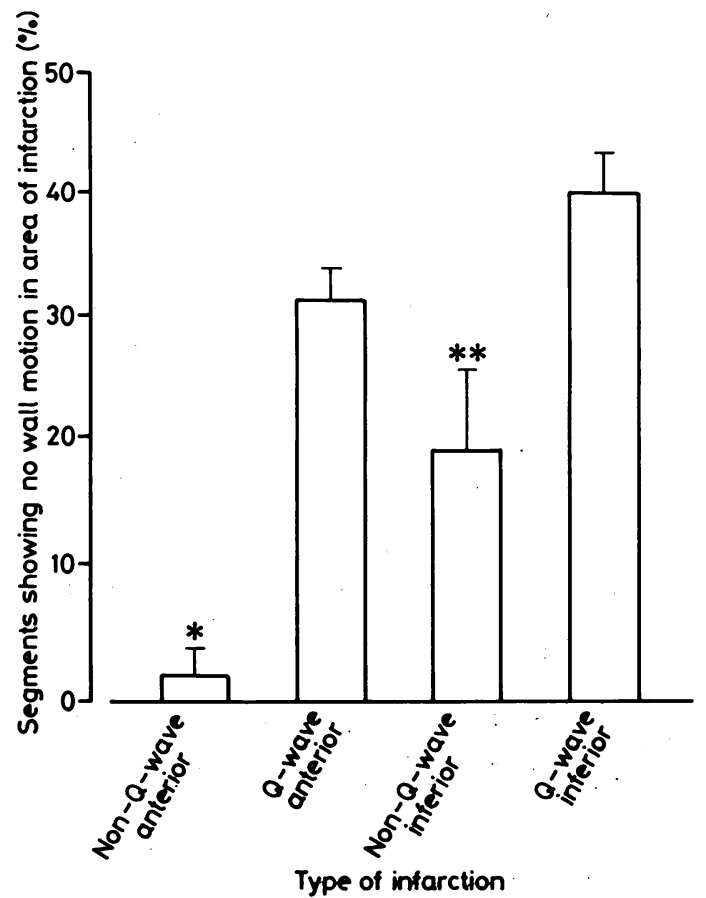

Fig 2 Wall motion abnormalities in the study group. The number of segments with absent wall motion expressed as a percentage of total anterior or inferior segments is shown. Patients with non- $Q$-wave anterior infarctions had the lowest frequency of segments with akinesis or dyskinesis. ${ }^{\star} p<0.01$ compared with all other:groups; ${ }^{\star \star} p<0.05$. compared with $Q$-wave inferior infarctions.

in $25.7 \%$ patients with non-Q-wave inferior infarction and in $50 \%$ of non-Q-wave anterior infarctions; however, this difference did not reach statistical significance $\left(\chi^{2}=3.7 ; 0.05<p<0 \cdot 10\right)$.

Absent wall motion in the area of infarction (fig 2 and table 3 ) was found in only $3 \%$ of segments in patients with non- $Q$-wave anterior infarctions. This was significantly less $(p<0.01)$ than the frequency found in all other groups including patients with non-Q-wave inferior infarctions. The group with non-Q-wave inferior infarction had a lower proportion of abnormal segments than the group with Q-wave inferior infarction (0.20 (0.4) vs 0.42(0.4); $\mathrm{p}<0.01$ ).

\section{Discussion}

The major finding of this study is the increased frequency of jeopardised myocardium in patients with an electrocardiographic pattern of a non-Q-wave anterior infarction. The results may be summarised by stating that half the patients with an anterior ST and $T$ pattern had preserved anterior wall motion distal to a lesion in the proximal or mid left anterior descending coronary artery. A similar pattern of residual myocardial jeopardy was found in approximately $\leqslant 25 \%$ of all other groups studied. The results reflect the reduced frequency of absent wall motion in the group with non-Q-wave anterior. infarction. Although their precise cause cannot be determined, these differences may be the result of the rich vascular supply of the interventricular septum from multiple septal branches and the relatively small area of anterior ischaemia required to produce ST and T changes.

Comparisons of haemodynamic data, hospital course, and prognosis of $Q$-wave and non- $Q$-wave infarctions have produced conflicting results. Some clinical studies have demonstrated no significant differences in one or more indices of severity including cardiac arrhythmias, congestive failure; or late mortality.$^{6-8}$ Other reports have suggested that there may be significant differences in the clinical course and prognosis of $\mathrm{Q}$-wave and non- $\mathrm{Q}$-wave infarctions. Patients with : acute non-Q-wave infarction have been reported to have less extensive cardiac necrosis. ${ }^{9-11}$ This group may, however, have a greater potential for late reinfarctions. Recurrent infarction was found in $21 \%$ of patients at nine months in a study by Hutter et al of 67 patients ${ }^{9}$ and in $18.4 \%$ of non-Q-wave infarction patients over a 30 month period in a recent study by Gibson et al. ${ }^{12}$ A long term study of 593 postinfarction patients has shown that early mortality: is proportional to the enzyme activities that reflect myocardial damage whereas late deaths are more common in the non-Qwave group. ${ }^{13}$ The presence of a non-Q-wave infarction was the best independent predictor of cardiac death in the third year after infarction. Residual $T$-wave change and postinfarction angina have also been reported to be of prognostic value. ${ }^{14}$

Recent studies have shown that in $<50 \%$ of nonQ-wave infarctions there is complete occhusion of the involved vessel during the first and second weeks. ${ }^{12} 15$ Patency of the infarct related vessel during the acute phase may predispose to recurrent infarction, perhaps on the basis of changes in vasomotor tone or occlusion by platelet aggregates or both. Angiographic evidence from the present study suggests that residual myocardial jeopardy in patients with non- $Q$-wave infarctions persists into the late postinfarction period. Coronary lesions proximal to the anterior or inferior segments with retained wall motion (normal or hypokinetic) were found in approximately $25-50 \%$ of cases. Progression to total occlusion in these vessels could result in a considerable loss of myocardial function 
and could contribute to the late mortality observed in some studies.

The present study has important limitations. Previous studies have shown that the presence of a $Q-$ wave or non-Q-wave pattern does not reliably predict the presence or absence of a transmural or non-transmural infarction. ${ }^{5}$ Patients with multiple infarctions or with electrocardiographic patterns reflecting changes in both anterior and inferior segments or a single anterior segment were excluded. The use of single plane angiography would not permit detection of myocardial damage localised to septal or lateral segments; however, the extent of impaired wall motion could be compared in patients with a similar distribution of electrocardiographic changes. Left ventricular function may have been improved in the group with non-Q-wave inferior infarction because of the increased number of patients receiving nitrates. ${ }^{16}$ Patients with complete occlusion of a coronary artery supplying the infarcted area would not be classified as having myocardial jeopardy from that area. Viable myocardium might then be perfused through collateral circulation. The number of patients with visible collaterals was similar in those with non-Q-wave anterior infarction, Q-wave anterior infarction, and non-Q-wave inferior infarction (table 1). Although patients with Q-wave inferior infarction had an increased frequency of collaterals, the percentage of left ventricular segments with absent wall motion was significantly higher in this group than in all other groups (table 3). Patients in the present study were randomised six months to five years after a myocardial infarction so that the results cannot be applied in the immediate postinfarction period.

With these restrictions this study provides an estimate of the frequency of myocardial jeopardy in patients with $Q$-wave and non-Q-wave electrocardiographic patterns after infarction.

\section{References}

1 Alderman EL, Fisher L, Maynard C, et al. Determinants of coronary surgery in a consecutive patient series from geographically dispersed medical centers. Circulation 1982;66(suppl I):I6-I13.

2 McKay RG, Aroesty JM, Heller GV, et al. The pacing stress test re-examined: correlation of pacing induced hemodynamic changes with the amount of myocardium at risk. J Am Coll Cardiol 1984;3:1469-81.

3 Buchwald $\mathrm{H}$. Clinical status of the partial ileal bypass operation. Circulation 1974;59(suppl I):I22-I37.

4 Spodick DH. Transmural vs nontransmural infarction [Letter]. Circulation 1980;62:447-8.

5 Spodick DH. Q-wave infarction versus $S-T$ infarction: nonspecificity of electrocardiographic criteria for differentiating transmural and nontransmural lesions. Am J Cardiol 1983;51:9-13.

6 Szklo M, Goldberg R, Kennedy HL, Touascia JA. Survival of patients with nontransmural myocardial infarction: a population-based study. $\mathrm{Am} \mathrm{J} \mathrm{Cardiol}$ 1978;42:648-52.

7 Taylor GJ, Humphries JO, Meollits ED, et al. Predictors of clinical course, coronary anatomy, and left ventricular function after recovery from acute myocardial infarction. Circulation 1980;62:960-70.

8 Thanavaro S, Krone RJ, Kleiger RE, et al. In-hospital prognosis of patients with first nontransmural infarctions. Circulation 1980;61:29-33.

9 Hutter AM, Desanctus RW, Flynn T, Yeatman LA. Nontransmural myocardial infarction: a comparison of hospital and late clinical course of patients with that of matched patients with transmural anterior and transmural inferior myocardial infarction. $\mathrm{Am} \mathrm{J}$ Cardiol 1981;48:595-602.

10 Cannon DS, Levy W, Cohen LS. The short and longterm prognosis of patients with transmural and nontransmural infarction. Am J Med 1976;61:452-8.

11 Madigan NP, Rutherford BD, Frye RL. The clinical course, early prognosis and coronary anatomy of subendocardial infarction. Am J Med 1976;60:634-41.

12 Gibson RS, Beller GA, Gheorghiade M, et al. The prevalence and clinical significance of residual myocardial ischemia 2 weeks after uncomplicated non- $Q$ wave infarction: a prospective natural history study. Circulation 1986;73:1186-98.

13 Krone RJ, Friedman E, Thanavard S, Miller JP, Kleiger RE, Oliver GC. Long-term prognosis after first Q-wave (transmural) or non-Q-wave (nontransmural) myocardial infarction: analysis of 593 patients. Am J Cardiol 1983;52:234-9.

14 Löfmark R. T wave changes and postinfarction angina pectoris predictive of recurrent myocardial infarction. Br Heart $J$ 1981;45:512-6.

15 DeWood MA, Stifter WF, Simpson CS, et al. Coronary arteriographic findings soon after non-Q-wave myocardial infarction. $N$ Engl J Med 1986; 315:417-23.

16 Swann HJ. Newer technologies for study of the action of nitrates in coronary circulation and myocardial function. Am Heart $J$ 1985;110(part 2):233-7. 